\title{
Toxinology and Brazil: a close connection
}

Ferreira Jr RS (1)

(1) Center for the Study of Venoms and Venomous Animals (CEVAP), São Paulo State University (UNESP - Univ Estadual Paulista), Botucatu, São Paulo State, Brazil.

In recent years, Brazil has developed a significant knowhow in oceanic oil exploration, distillation and purification of its derivatives, such as gasoline and biodiesel. Similarly, aeronautic industries, banking automation companies, metal-mechanic industries, complexes of paper and cellulose exploration, computing market, agriculture and livestock industries among others have been sold, mainly to other developing countries, for significant profits.

Recently, Toxinology became a significant research field for Brazilian science during the first half of 2012. There were two major reasons for this. Firstly, due to the relevance of research in this area produced by Brazilian professionals and represented by the increased number of plenaries, concurrent sessions and poster presentations during the 17th World Congress of the International Society on Toxinology (IST), Venom Week 2012 meeting, and 4th International Scientific Symposium on All Things Venomous that were held in Honolulu, Hawaii, USA, from July 8 th to 13 th.

The target audience consisted of scientists that work with toxins from animals, plants and microorganism; medical researchers and practitioners; veterinarians; zoo and collection management personnel; herpetologists and others with an interest in natural toxins.

The event had over 300 scientific presentations in a wide diversity of toxinologic subjects on:
- toxin proteomics and genomics

- toxin pharmacology and physiology

- toxins as leads for drug development

- venoms, antivenoms and other antidotal agents

- clinical toxinology - envenomations and management

- exotic venomous animals and management of non-native bites/stings

- venomous animal husbandry - zoos, universities, quasi-public and private collections

- veterinary toxinology.

The second reason is the recognition of a respected English publisher, which realized the importance and progress of this area and invited JVATiTD to join its select group of scientific journals. This negotiation has been going on for over 12 months and was recently approved by the Superior Council of our University and endorsed by the president of UNESP. Now, the partnership with Springer/BioMed Central is official and soon our content will be available at http://www. biomedcentral.com/journals.

JVATiTD publishes manuscripts in the emerging fields of Toxinology and Tropical Diseases, and constitutes an important producer and consumer of information on both subjects. Such partnership prominently features another Brazilian Journal in the international scenario. 
With this visibility, it is expected that the journal impact factor will gradually increase, particularly after the future indexing by PubMed. This scenario will certainly contribute to the internationalization of Brazilian science.

We ask all colleagues to support this new stage in the short life of our Journal.

Finally, the relevant results of Brazilian international insertion, the World Congress of Toxinology and the agreement between JVATiTD and $\mathrm{BMC} /$ Springer, show the importance of having competent and strong international partnerships.

\section{COPYRIGHT}

(C) CEVAP 2012

\section{SUBMISSION STATUS}

Received: August 13, 2012.

Accepted: August 14, 2012.

Full paper published online: August 31, 2012.

\section{CORRESPONDENCE TO}

Rui Seabra Ferreira Junior, Centro de Estudos de Venenos e Animais Peçonhentos (CEVAP), UNESP, Fazenda Experimental Lageado, Rua José Barbosa de Barros, 1780, Botucatu, SP, 18610307, Brasil. Phone/fax: +55 1438145555 and 55 143880 7241. Email: rseabra@cevap.org.br. 